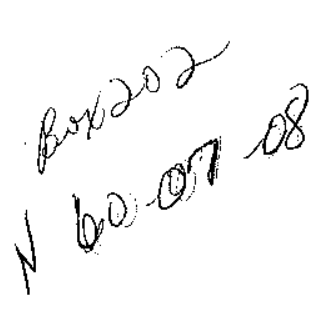

\title{
REMOVAL OF SLUDGE FROM HIGH ACTIVITY WASTE TANKS
}

\author{
A. J. HILL, Jr.
}

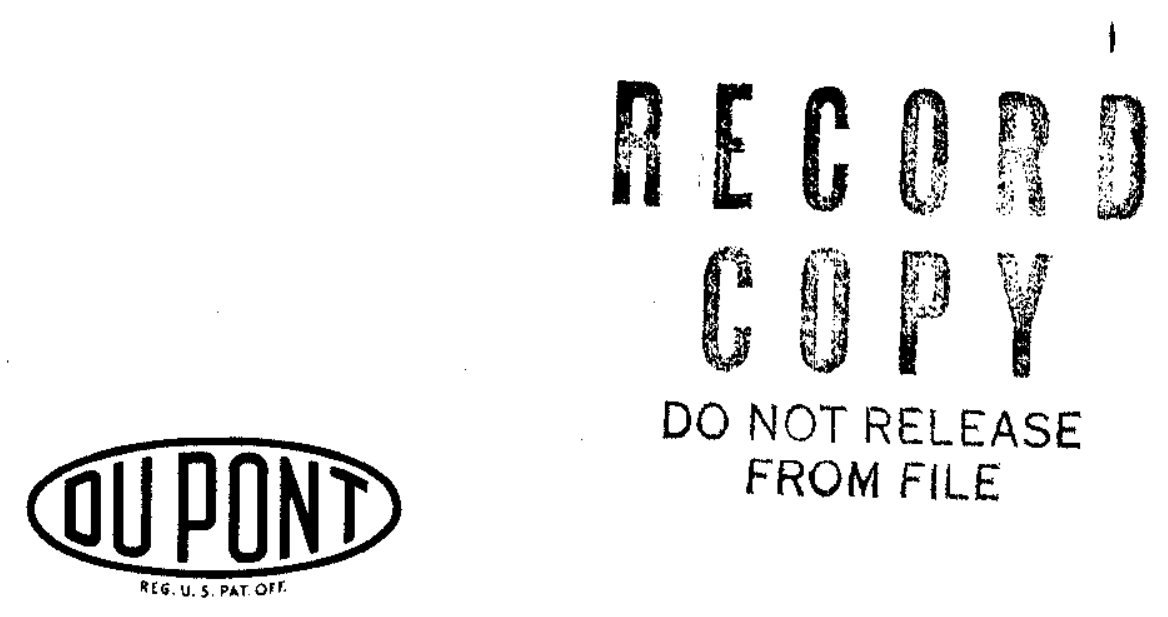

Savannah River Laboratory

Aiken, South Carolina 


\section{LEGAL NOTICE}

The report was prepared at en accouss of Goversment sponeored work. Nelthat the Unitod

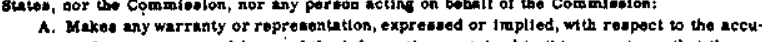
recy, completenes.s. or unotuipes.

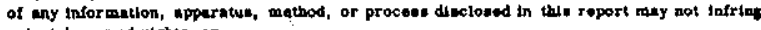
privatoly omsed rights; or

B. Anoumes any limbtlities with respect to the une of, or tor damages resuliting from the ne of any informatson, apparatus, metbod, or procesu dieclomed to this report.

Ae uesd In the above, "person acting or behalt of the Comminetion" Inciudes any employes or contractor of the commisulon. or employee of ench contractor, to the extont hast

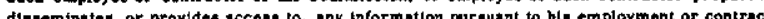
with the Commineion, or his esmaployment with euch contrector.

Printed in the United States of America

Available from

Clearinghouse for Federal Scientific and Technical Information National Bureau of Standards, U. S. Department of Commerce Springfield, Virginia 22151

Price: Printed Copy $\$ 3.00 ;$ Microfiche $\$ 0.65$ 
DP-1093

Waste D1sposal and Processing

(TID-4500)

\title{
REMOVAL OF SLUDGE FROM HIGH ACTIVITY WASTE TANKS
}

\author{
by \\ Arthur J. Hill, Jr.
}

Approved by

D. S. Webster, Research Manager

Separations Englneering Division

July 1967

E. 1. DU PONT DE NEMOURS \& COMPANY SAVANNAH RIVER LABORATORY

AIKEN, S. C. 29801

CONTRACT AT(07.2)-1 WITH THE

UNITED STATES ATOMIC ENERGY COMMISSION 


\begin{abstract}
Aqueous radioactive wastes from the separations processes at the Savannah River Plant are stored underground in large, carbon steel tanks, and cooled by water flowing through a network of vertical and horizontal cooling colls. To conserve space, the supernatant solutions are removed perlodically from the tanks, concentrated by evaporation, and transferred to other tanks for long-term storage. During storage of the wastes prior to concentration, precipitated sludge accumulates in the bottom of the tanks. Equipment and techniques that have been developed for removal of sludge from waste tanks are described in this report. High velocity jets of water are used to disperse the sludge into a slurry that can be removed with centrifugal pumps. The development program culminated in removal of sludge from two waste tanks. The second test, incorporating the results of experience gained in the first, was the more successful; greater than $95 \%$ of a 1.5 -foot layer of sludge was removed during five hours of operation.
\end{abstract}




\section{CONTENTS}

$\underline{\text { Page }}$

List of Figures . . . . . . . . . . . . . 4

Introduction................. 5

Summary ................... 5

Discussion................. 6

High Activity Waste Storage Tanks. . . . . 6

High Activity Waste Sludge . . . . . . 6

Experimental Facilities........... . 9

Experimental Results . . . . . . . . . 10

Range of Jets........... . 10

Pumps . . . . . . . . . . . . 12

Arrangement of Nozzles . . . . . . . 14

Rotation of Nozzies ......... . 14

Tests in Plant Waste Tanks .... . . . . 17

Equipment and Arrangement . . . . . . 17

Sludge Transfer Operation ........ 21

Closed Circuit Television . . . . . . 26 


\section{LIST OF FIGURES}

Figure

Page

1 Underground Liquid Waste Storage Tank . . . 7

2a Horizontal Cooling Coils . . . . . . . 8

$2 \mathrm{~b}$ Vertical Cooling Coils .......... 8

3 Concrete Test Tank . . . . . . . . . 9

4 Platforms for Pump and Nozzle Assemblies

Supported on Poles over the Test Tank . . . 10

5 Range of Water Jets from 1/4-inch Nozzles

in Wet Clay. . . . . . . . . . . . . . ll

6 Air-Operated Sump Pump with Skirt Attached . . 12

7 Characteristics of Sludge Transfer Pump . . . 13

8 Mechanical Rotation of Nozzles . . . . . 15

9 Jet Suspended from 40-foot Tower . . . . . 16

10 Arrangement for Sludge Removal . . . . . . 17

Ila Centrifugal Pump and High Pressure Nozzle Assembly ................. 18

Ilb Installation of Centrifugal Pump and Nozzle Assembly . . . . . . . . . . . . . . 19

Shielding for Sludge Removal . . . . . 20

13 Pipes and Controls for Sludge Removal . . . 20

14 Sludge Transfer Data . . . . . . . . 22

15 Bottom Area of Tank after Sludge Removal . . 23

16 Removal of Nozzle and Pump Assembly . . . . 24

17 Television Cameras and Lights . . . . . . 27 


\section{REMOVAL OF SLUDGE FROM HIGH ACTIVITY WASTE TANKS}

\section{INTRODUCTION}

During the storage of aqueous radioactive wastes in cooled, underground tanks, a layer of sludge accumulates at the bottom of the tanks. After several years, the sludge occupies about $10 \%$ of the working volume of the tank. To defer the need for additional tanks, the supernatant solutions are removed from the tanks, concentrated by evaporation, and transferred to other tanks for long-term storage in immobile, semisolid form.

Although it has not been necessary to remove sludge before, a feasible method of removal may be needed to (1) transfer the sludge to permanent storage in a bedrock vault, (2) uncover the bottom horizontal cooling coils before adding fresh waste, (3) redistribute the sludge among the tanks, or (4) remove the sludge from a leaking tank.

The removal of sludge is made difficult by a network of horizontal cooling coils located close to the bottom of the tanks.

\section{SUMMARY}

One promising methad for removing sludge from a high activ1ty waste tank is the use of high velocity jets of water to suspend the sludge for a sufficient time to allow the slurry to be pumped from the tank. The development program described in this report proved the feasibility of the method. The experimental work also provided the necessary data on the size, arrangement, and angle of the discharge nozzles, the pressure required for the jet action to reach all of the bottom area of the tanks, the arrangement and capac1ty of centrifugal pumps to remove the slurry, and the methods of operation needed to obtain the desired results with minimum volume of water.

The experimental program was concluded with two trials in plant waste tanks. In the first, approximately 90\% (43,000 gallons) of intensely radioactive sludge was transferred from one high activity waste tank to another. More of the sludge could have been transferred, but the test was terminated to save time and to avoid the use of an excessive volume of water. 
After the removal of the sludge from the first tank, improvements in the equipment and techniques were developed and were demonstrated in a semiworks test with nonradloactive materlal. These improvements allowed the transfer of nearly all of the radioactive sludge from a second tank.

Sludge can now be removed from high act1vity waste tanks as needed and the procedures that were developed are acceptable for plant use.

\section{DISCUSSION}

\section{HIGH ACTIVITY WASTE STORAGE TANKS}

Aqueous high activity wastes from the separations processes are stored in two types of carbon steel tanks. The first type is a 750,000-galion vessel, 75 feet in diameter by 24 feet high, containing 12 support columns and horlzontal and vertical cooling colls. The second type is similar to the first except that it is 85 feet in diameter, has a capacity of one militon gallons, and has only one support column located in the center. A plan view and sectional elevation of the 75-foot-diameter tank are shown in Figure 1.

The horizontal coils are two sets of 2-inch carbon steel p1pes, arranged at right angles to each other (Figure 2a). The centerline of the bottom set is 2 inches from the bottom of the tank (clearance less than one inch) and the other is 5 inches. Pairs of 2-inch vertical colls, hung from the top of the tank, loop up and down in rows 4 feet apart and diagonal to the bottom colls (Figure 2b). The bottom loops of the vertical coils are fastened to the bottom of the tank and are within an inch of the upper rows of horizontal colls. The supply and return Iines of all the coils are in a vertical cluster under a valve house on top of each tank. The cooling system in each tank comprises nearly four miles of pipe.

\section{HIGH ACTIVITY WASTE SLUDGE}

The sludge that precipitates in a tank during aging of high activity waste normally amounts to about 100,000 gallons and occupies about one-tenth of the tank volume. About threefourths of the sludge is compacted into a dark brown, sticky mass; and one-fourth is loosely settled, finely divided material of essentially the same composition. The compacted sludge is generally quite moblie but tends to adhere strongly to objects, such as inserted samplers. The adhering sludge usually is not removed by raising an object through the supernate, but can be removed readily by flowing water. 

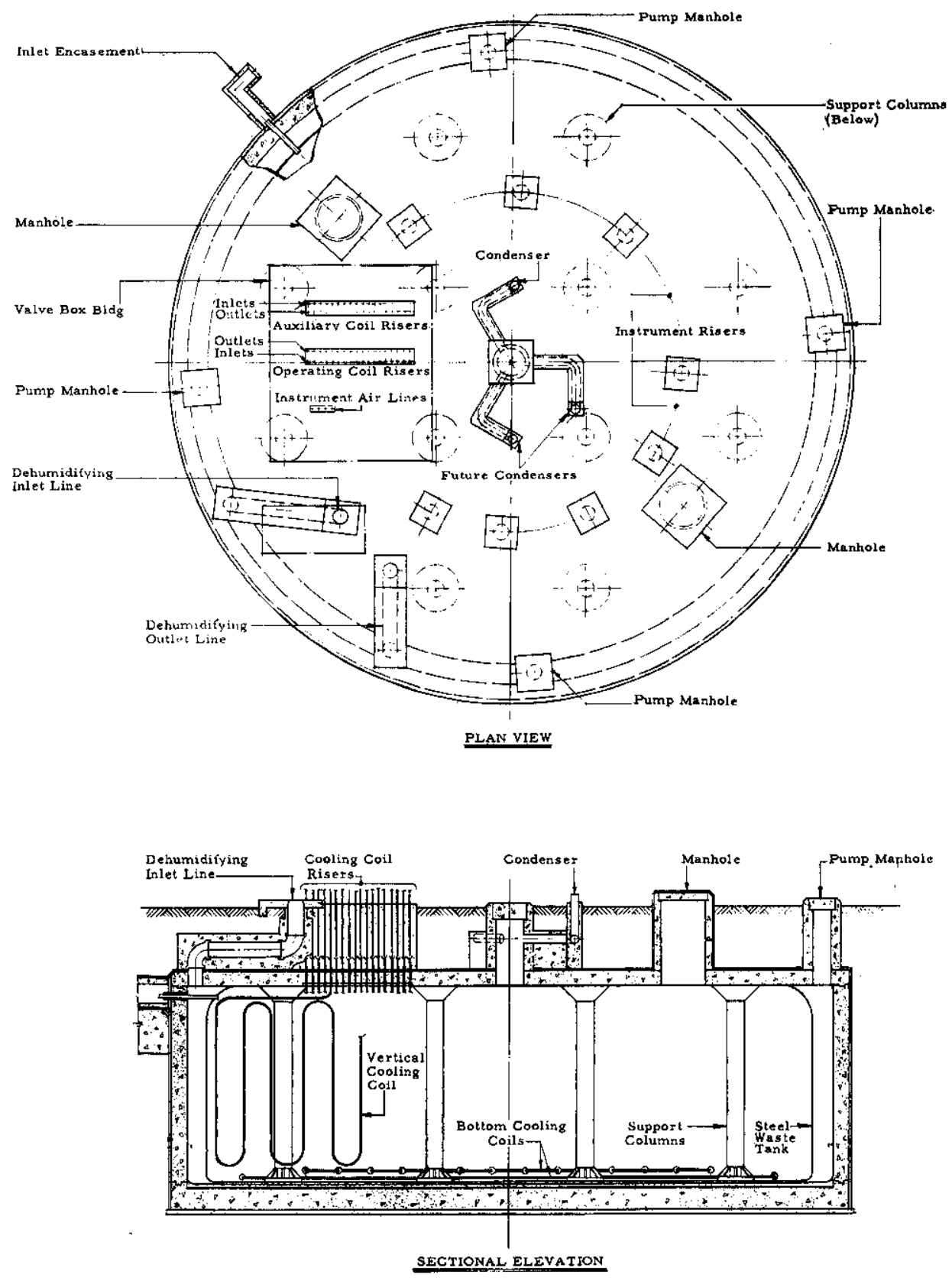

FIG. I UNDERGROUND LIQUID WASTE STORAGE TANK 


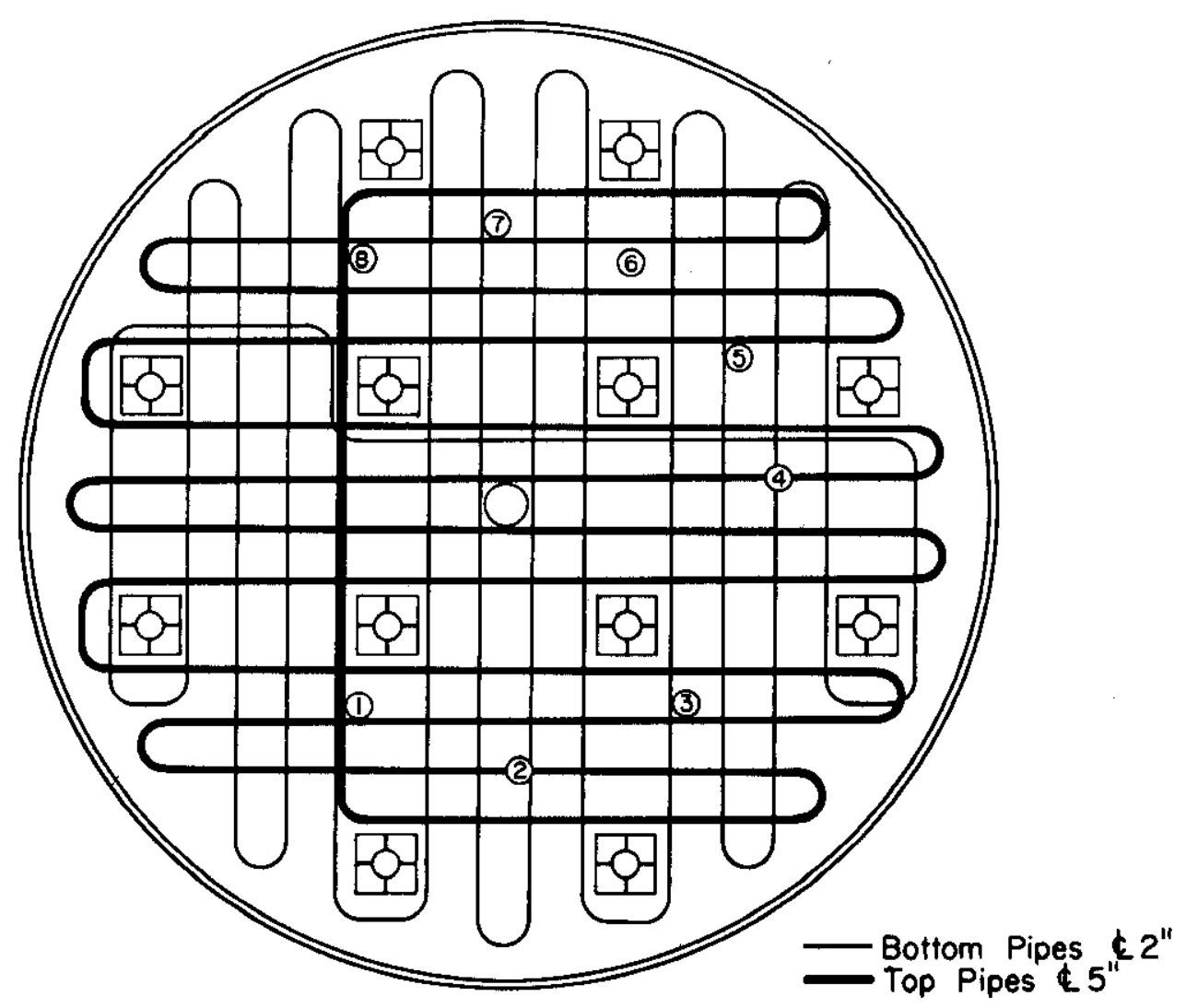

FIG. 2a. HORIZONTAL COOLING COILS 75 - $\mathrm{ft}$ - diameter waste tank

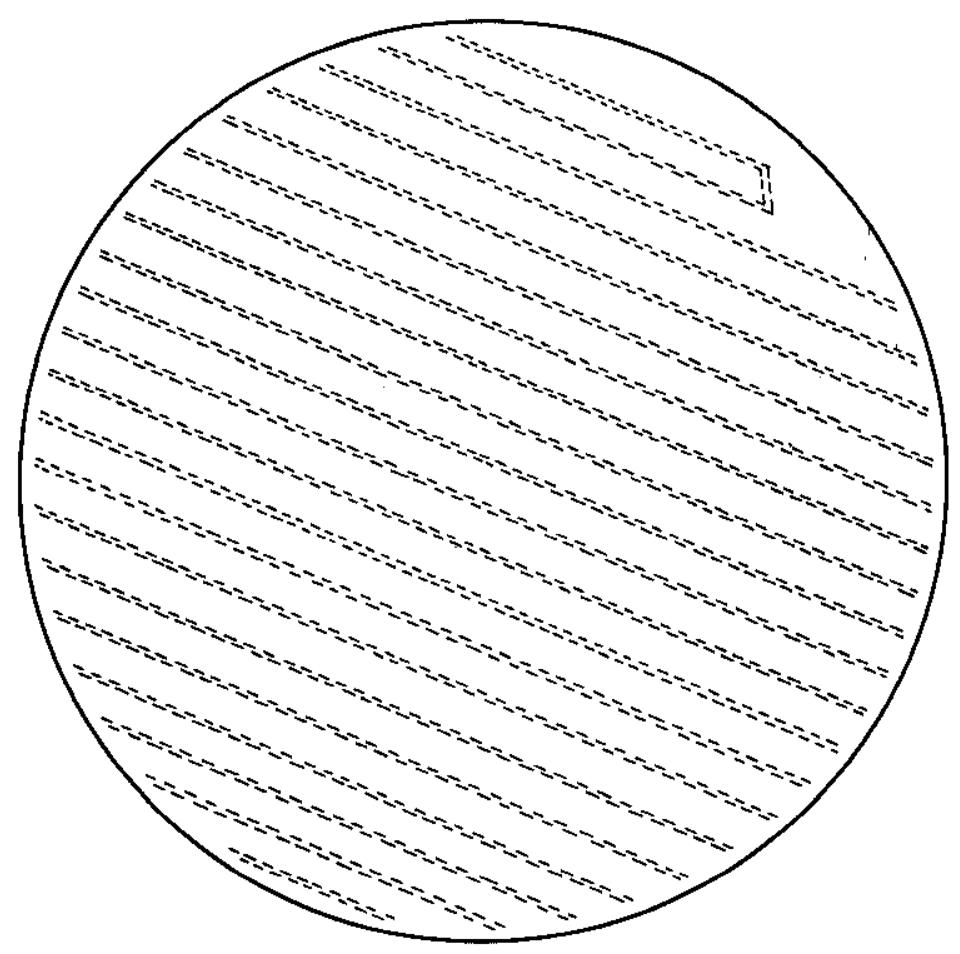

FIG. 2b. VERTICAL COOLING COILS 
The solids comprise a mixture of oxides and hydroxides of manganese, iron, and some aluminum, plus uranium, plutonium, and mixed fission products. The exact composition and radioactive content of sludge in any tank depends upon the process history of materials in the waste, and upon the age of the sludge.

\section{EXPERIMENTAL FACILITIES}

Preliminary tests were made in an open steel tank, 8 feet in diameter, with a mixture of fine sand and clay as a stand-in for radioactive sludge. These tests showed that it should be feasible to slurry sludge with high velocity jets of water discharged horizontally from nozzles of small diameter located underwater close to the bottom of the tank. Slow rotation of the nozzles provided the sweeping action needed to clean the bottom. Efforts to pump out the slurry were not successful because the force of the jet stream in the confinement of the small tank drove the slurry away from the pump. Discharging the nozzles downward from above the surface of the liquid was not suitable because most of the impact of the jet streams was dissipated at, or near, the surface.

A mockup representing one-half of the bottom of a 75-footdiameter waste tank was constructed of a wall of cement blocks 32 inches high on a concrete slab. The mockup included horizontal cooling coils of 2-inch-diameter pipe and simulated bases of six of the twelve supporting columns of a waste tank (Figure 3). Portable platforms with movable catwalks were

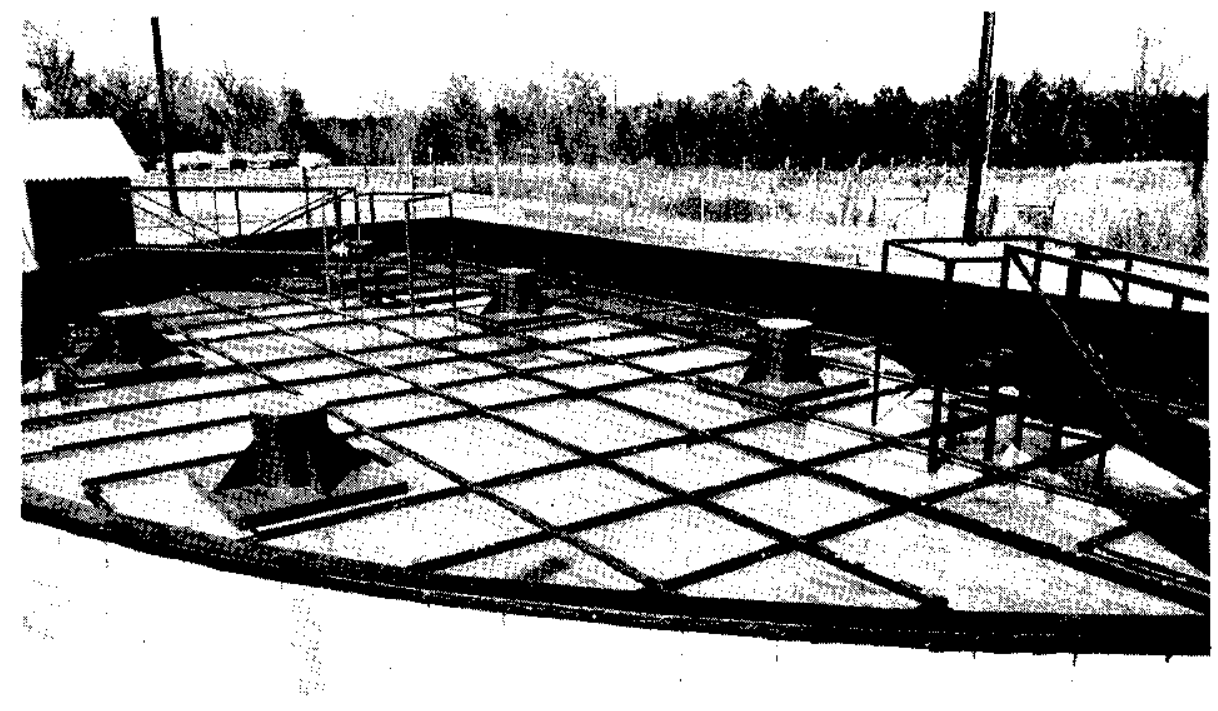

FIG. 3 CONCRETE TEST TANK 
used to position the nozzles and portable sludge pumps at appropriate locations to correspond to available access ports or risers in the top of the waste tanks. Wet, settled clay (kaolin) was used to simulate radioactive sludge.

In the first four tests, a cluster of angle-iron supports for the platforms surrounded the nozzles and caused interferences very close to the nozzles. The interferences were greater than those anticipated in the actual waste tanks. In the next two tests, the catwalks and platforms were supported on poles that bridged the test tank (Figure 4).

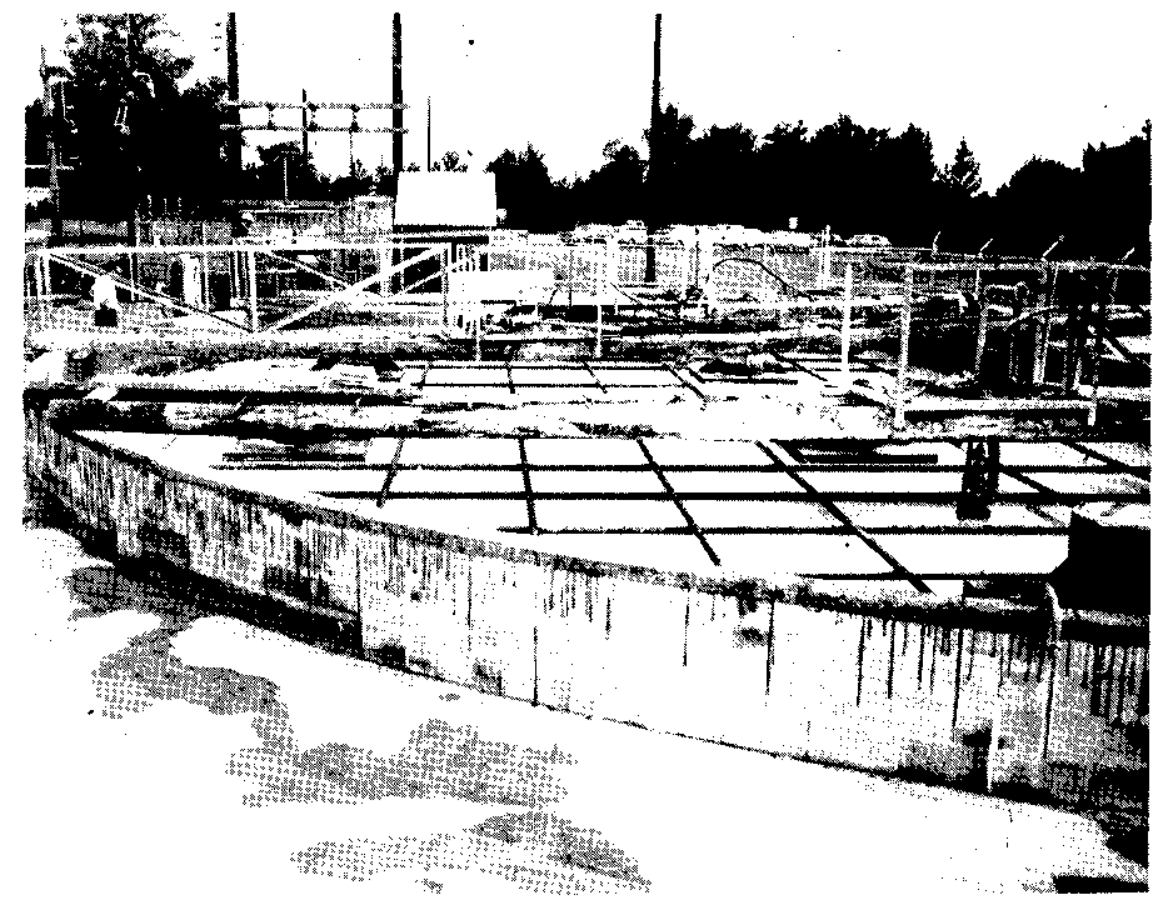

FIG. 4 PLATFORMS FOR PUMP AND NOZZLE ASSEMBLIES SUPPORTED ON POLES OVER THE TEST TANK

\section{EXPERIMENTAL RESULTS}

\section{Range of Jets}

The ranges of jets from submerged nozzles of $1 / 8_{-}, 3 / 16-$, and $1 / 4$-inch diameter were determined in 8 inches of wet clay at pressures from 500 to 3000 psig. The nozzles were positioned to discharge horizontally $1 / 2$ to $3 / 4$ inch above the bottom of the tank, and either were braced against a wall of the tank for individual testing or were mounted in pairs discharging in opposite directions (to balance the thrust). With no horizontal pipes in front of the jet streams, the clay was 
cleaned completely from the path of the jets to distances from 6 feet ( $1 / 8$-inch nozzle at $500 \mathrm{psig}$ ) to about 30 feet ( $1 / 4-$ inch nozzle at $3000 \mathrm{psig}$. Superficial mixing of the clay was evident for an additional 25 to 30 feet, but the clay on the bottom of the tank was not disturbed in this region.

When the jets were directed under the upper rows of hor1zontal pipes and parallel to the plpes close to the bottom, the effective ranges were not significantly reduced from those observed without the pipes. With the jets directed under the bottom rows of pipes, the ranges of the 1/8- or 3/16-inch nozzles were not reduced significantly, but the maximum range of the 1/4-inch nozzles was reduced by about half. However, these tests showed nozzles with orifices less than $3 / 16$ inch in diameter would not provide the range, even at 4000-psig pressure, to reach the walls of the tank from locations ava11able for introducing the nozzles into the waste tanks.

Further tests with 1/4-inch nozzles under 10 inches of wet clay, and at pressures of 500 to $4000 \mathrm{psig}$, were made to define the range with respect to the angle between the jet discharge and the two sets of horizontal pipes. As indicated in the preliminary tests, the maximum effective range is obtained when the jet stream is parallel to the bottom set of pipes and the flow is channeled between the bottom pipes. The range is reduced somewhat when the jet is directed under and perpendicular to the bottom pipes, although a broader area is covered because the bottom pipes flatten the stream. The area is broadest with the jet streams diagonal to the pipes, but the range is shortest.

As shown in Figure 5, the effective range in wet clay

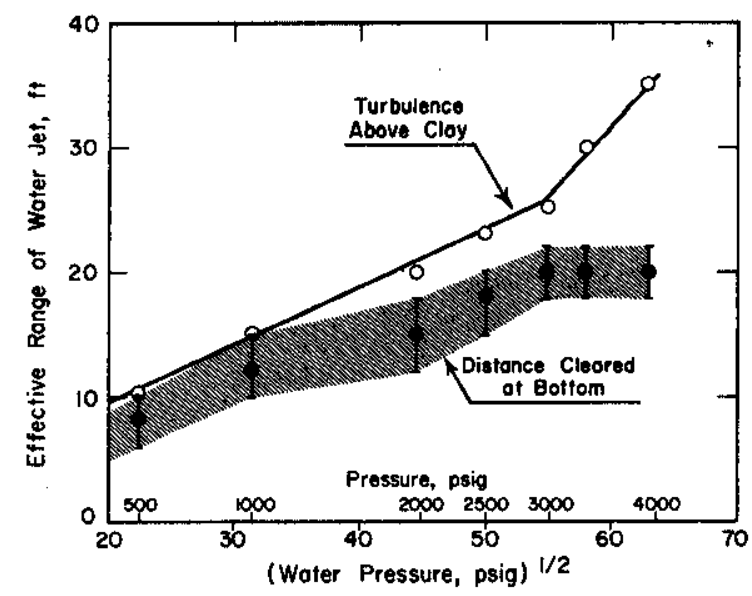

FIG. 5 RANGE OF WATER JETS FROM 1/4-INCH NOZZLES IN WET CLAY 
increased from about 8 feet at $500 \mathrm{psig}$ to 20 feet at 3000 psig. The range at which turbulence was evident above the clay increased from about 10 feet at 500 psig to 25 feet at 3000 psig. Higher pressure, to $4000 \mathrm{psig}$, did not extend the bottomcleaning range, but markedly increased the range of surface turbulence; apparently, the jet of water rides up over the clay at about 20 feet and continues on the surface.

\section{Pumps}

For the experiments conducted in the concrete test tank, air-powered multivane sump pumps of 250 -gpm capacity were used. Pumpout tests with clay slurry showed that the intake grilis of the pumps prevented reduction of the fluid level to less than 3 to 4 inches; air was sucked in even when the pumps were throttled as much as possible. Consequently, "skirts" were attached around the intake section of the base of the pumps (Figure 6) to allow reduction of the level in the tank to about 1 inch.

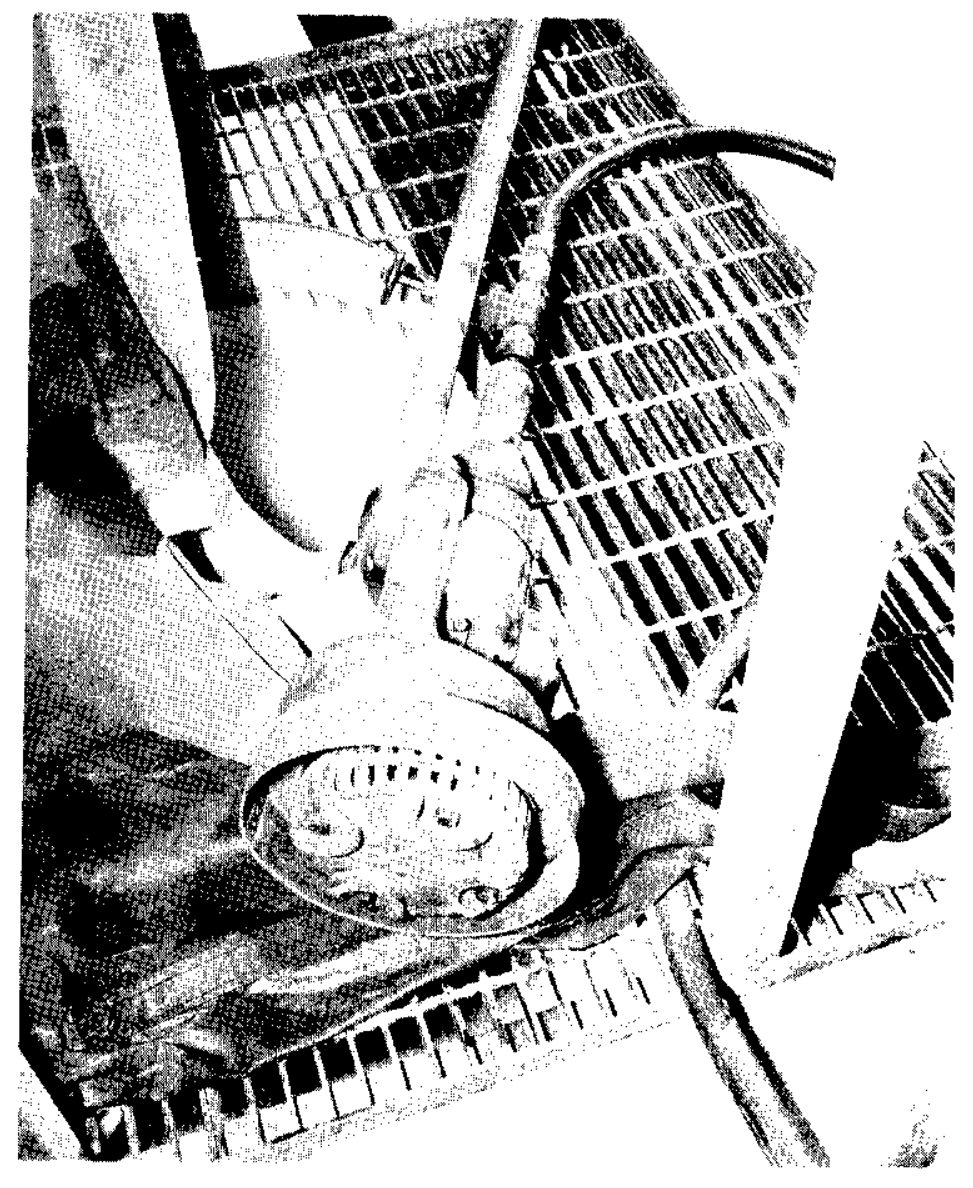

FIG. 6 AIR-OPERATED SUMP PUMP WITH SKIRT ATTACHED 
The air-powered pumps used in the test tank could not provide the lift required to remove sludge from a waste tank; 25-hp totally submerged centrifugal pumps were selected. Semiworks tests with water confirmed that the performance of the centrifugal pumps was as specified by the manufacturer. As with the sump pumps, the inlet screen of the centrifugal pumps was about 6 inches high, so a skirt was added to the pumps to extend the suction to within 1 inch of the bottom. The measured capacity of the pumps was not significantly reduced by the skirt (Figure 7).

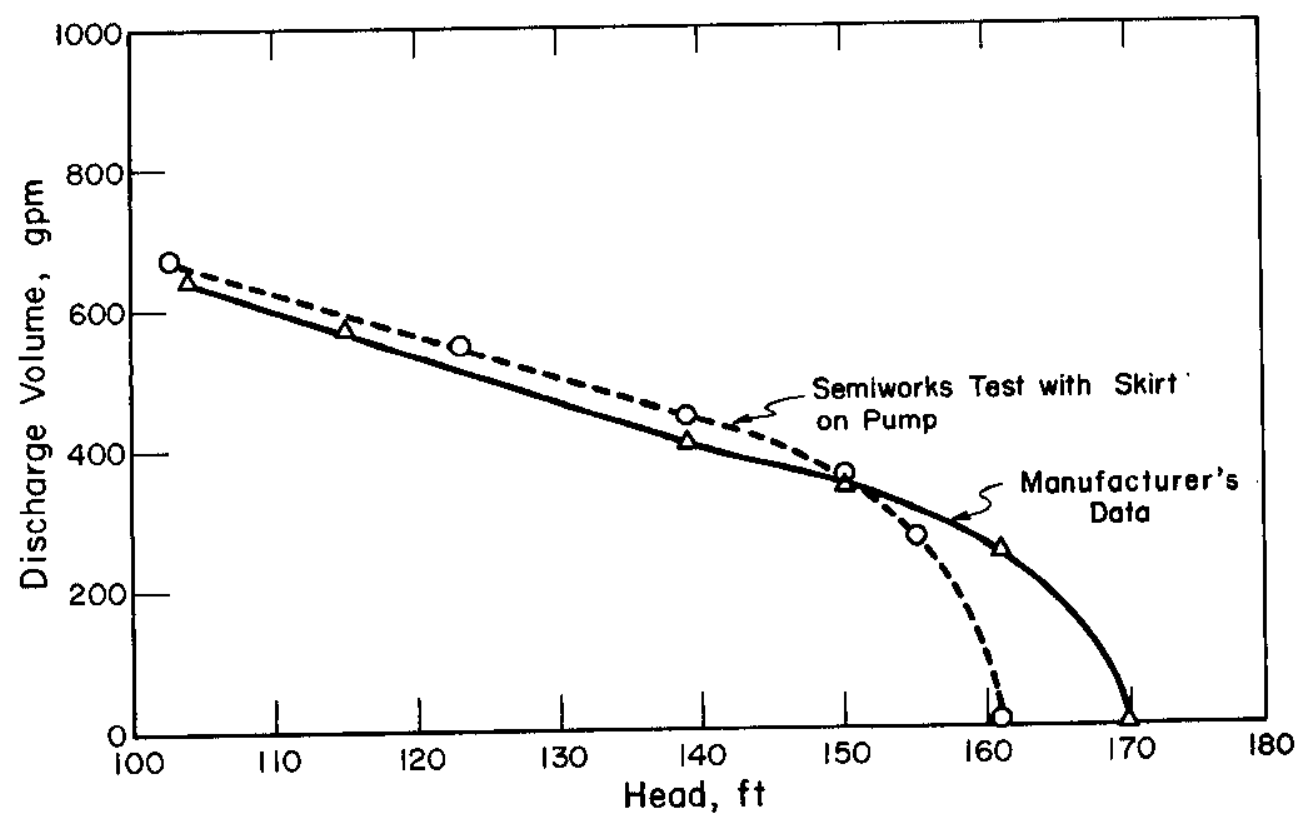

FIG. 7 CHARACTERISTICS OF SLUDGE TRANSFER PUMP

Pumpout tests showed quite clearly that the best location for a pump was adjacent to the nozzle, where the circulation induced by the jet could carry slurry back to the pump. When the pump was located away from the nozzles, considerable time was required (even at high pressure) for the jet streams to penetrate the clay between the nozzle and the pump. Before penetration was achieved, the pump recelved only slurry traveling over undisturbed clay on the bottom. Thus a cleared area was pushed up around the nozzles and drawn down for a few feet around the pump, but a ridge was left between the nozzles and the pump. Considerably more time was required at high pressure to reduce the ridge, and consequentiy a larger volume of water than was needed to clear an equivalent area with the pump adjacent to a set of jet nozzles. 


\section{Arrangement of Nozzles}

In early tests, an arrangement of four $1 / 8$-inch nozzles $90^{\circ}$ apart proved to be significantly more effective in slurrying clay than a pair of nozzles discharging in opposite directions. With slurry returning between the four nozzles, a cloverleaf pattern was established that produced very effective mixing. However, similar arrangements with the large nozzles needed for greater range (such as four 3/16-inch nozzles, or two $1 / 4$-inch with two 1/8-inch nozzles) were not as effective as two $3 / 16$ or 1/4-inch nozzles discharging in opposite directions. With two large nozzles, slurry flowed rapidly back to the nozzles in a direction normal to the discharge streams and good mixing was obtained. With four large nozzles at $90^{\circ}$ or even with two large and two small nozzles, the return pattern was not well defined and the outward flow was large enough to cause a marked depression in fluid depth adjacent to the nozzles. The decreased depth allowed the pumps to draw in air, resulting in loss of efficiency.

\section{Rotation of Nozzles}

In most of the experimental program and in the first plant test, the nozzles were rotated manually by turning the vertical water supply pipe. Uniform rotation of the jets by a simple sprocket-and-chain drive powered by an electric motor and simple gear reducer (Figure 8) proved to be more effective both in slurrying clay and subsequently in the removal of sludge in the second plant test. Mechanization of the jets reduces the manpower required to remove sludge from a tank and hence reduces the potential for radiation exposure of personnel per.. forming such operations.

Periods of rotation shorter than 2 minutes were clearly less effective than longer periods, even with only 500-psig water pressure. Best results were obtained with rotational periods of about 5 minutes for longer ranges and higher pressures. These rates are within the range of the variable gear drive without change of sprocket. At all pressures, the action of the jet streams in clearing clay from the bottom of the test tank and in returning slurry to the pump adjacent to the jet nozzles was much more effective in tests with the continuous, steady, mechanical. rotation than in tests where the nozzles were rotated manualiy.

During a pumpout test, with only one pair of nozzles (2800 psig), the nozzles were rotated in one direction until about 1 slurry-volume (17,600 gallons) of clay had been pumped and lit- 


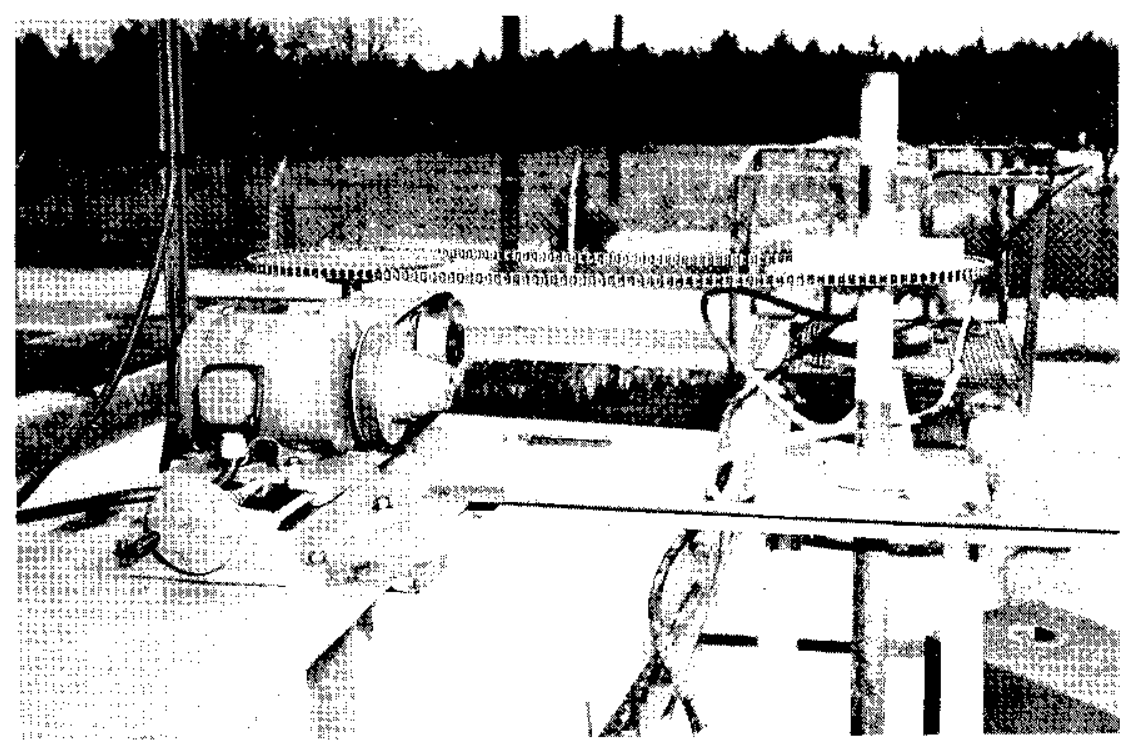

ROTATIONAL DRIVE

Safety Guard Removed

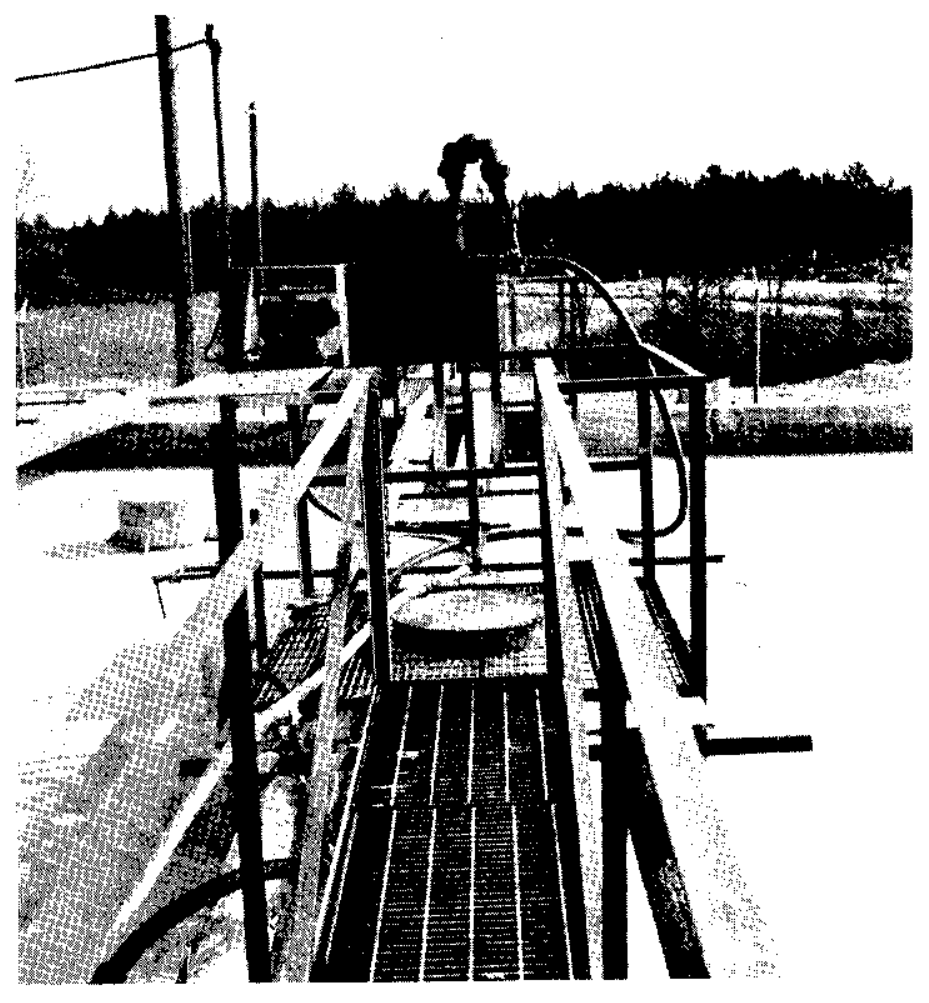

ROTATING JET OPERATION

Semiworks Test Tank

FIG. 8 MECHANICAL ROTATION OF NOZZLES 
tie further change was occurring in the total area cleared by the jet streams. An estimated $60-70 \%$ of the original volume of clay was removed under these conditions. When the direction of rotation was reversed and an additional 10,000 galions of water was used, the area cleared was extended by several feet, to about 75\% removal of the original clay. The greatest effect was evident in areas behind the simulated bases of columns, where the change in the direction of the approaching jet streams removed clay that had been washed over behind one side of the column during the previous perlod. Periodic reversal in the direction of rotation was recommended for routine operation.

The bottoms of the waste tanks are 35 to 40 feet below ground level. To be sure that the thrust of the jets could be satisfactorily handled by pairs of jets back-to-back, and that local obstruction close to one nozzle or operation in and out of water would not upset this balance, a test was conducted with a pair of nozzles connected to a 40-foot length of $1-1 / 2$-inch heavy-duty water supply pipe suspended vertically from a temporary scaffold (Figure 9). At 3000 psig in clay-water slurry

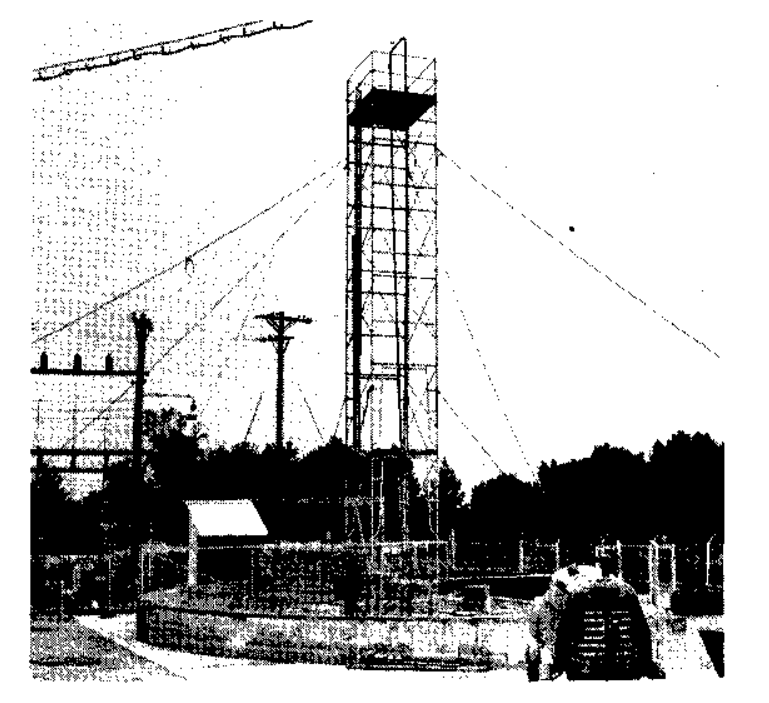

FIG. 9 JET SUSPENDED FROM 40 - FOOT TOWER

there was no vioient displacement of the nozzles whether discharging in air, in clay, or in clay-water slunry, even when there was an obstruction near the nozzle. There was an occasional slow, gentle displacement of the pipe for 3 or 4 inches in a direction normal to the discharge of the nozzles, but each time the pipe returned to a steady state in the original position. Nevertheless for the plant trials the 1-1/2-inch pipes to the nozzles were fitted with a collar that was fastened to the $3-$ 
inch vertical discharge line from the centrifugal punps; this arrangement expedited handling of the long, slender pipe assemblies with a boom crane and assured the proper relative positions of the pump and nozzles in the waste tanks.

\section{TESTS IN PLANT WASTE TANKS}

\section{Equipment and Arrangement}

In the first plant test, approximately $90 \%$ of the original 48,700 gallons of sludge in Tank 2 in one of the waste storage areas was transferred to Tank 7 (Figure 10a) by the high-velocity jet technique. Six high pressure pumps were rented from Dow Industrial Service to provide water for the jets.
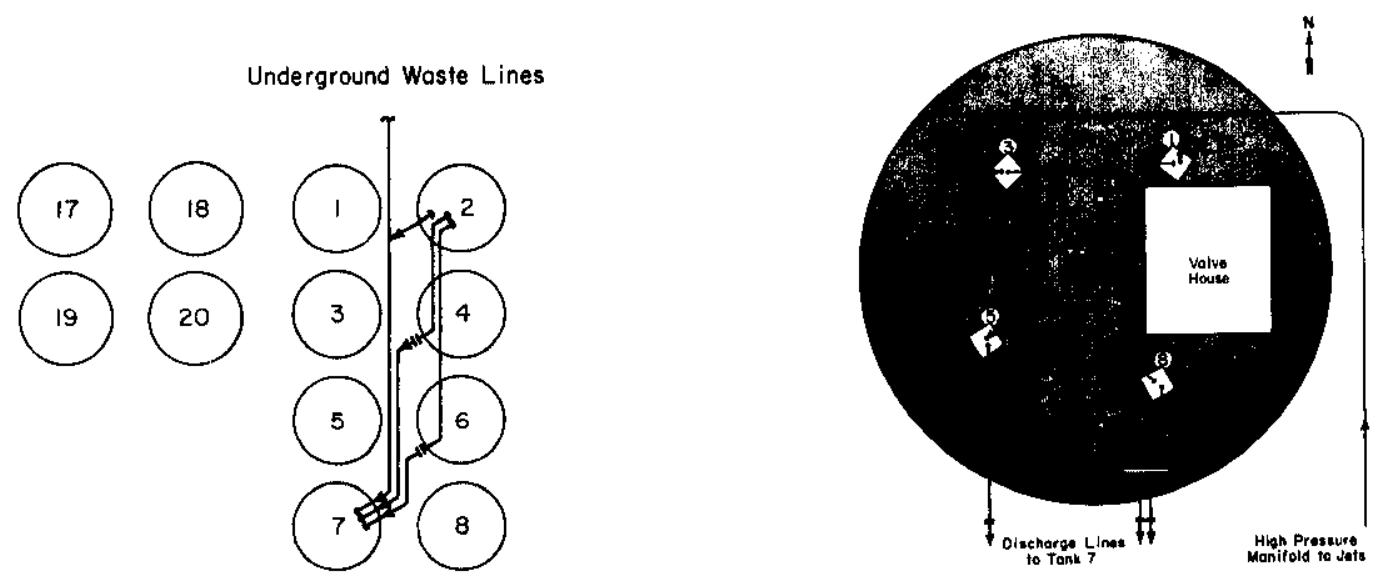

o. Waste Tanks in F Area

b. Special Connections at Tank 2

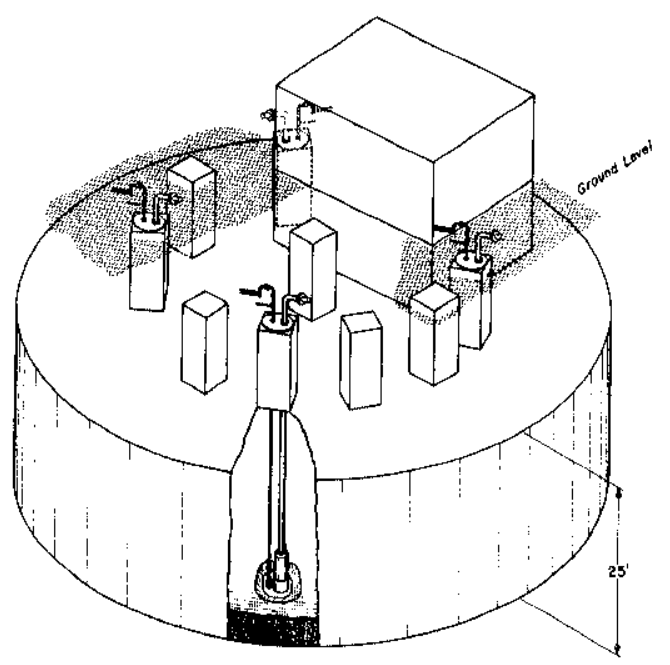

c. Jets and Pumps in Tank 2

FIG. 10 ARRANGEMENT FOR SLUDGE REMOVAL 
A pair of 1/4-inch nozzles, arranged to discharge in opposite directions parallel to the bottom of the tank and very close to it, was inserted in each of four access riser pipes, numbers 1, 3, 5, and 8, in Tank 2 (Figure 10b). During the sludge removal operation, the nozzles were rotated horizontally at an overall rate of one-half turn per hour -- by manually turning the vertical water supply pipe to each pair of nozzles in increments of 15 degrees every 5 minutes.

A 25-hp centrifugal pump was also installed through each of the risers along with the nozzles (Figure 11), and was suspended approximately 3 inches above the bottom of the tank to avoid interference with the jet streams from the nozzles. The discharge line from the pump at Riser 5 was connected directly to the existing shielded header from Tank 2 to Tank 7 . The discharge lines from the other three pumps were combined in a manifold from which two pipes were connected to existing shielded headers from other tanks ( 4 and 6) to Tank 7 .

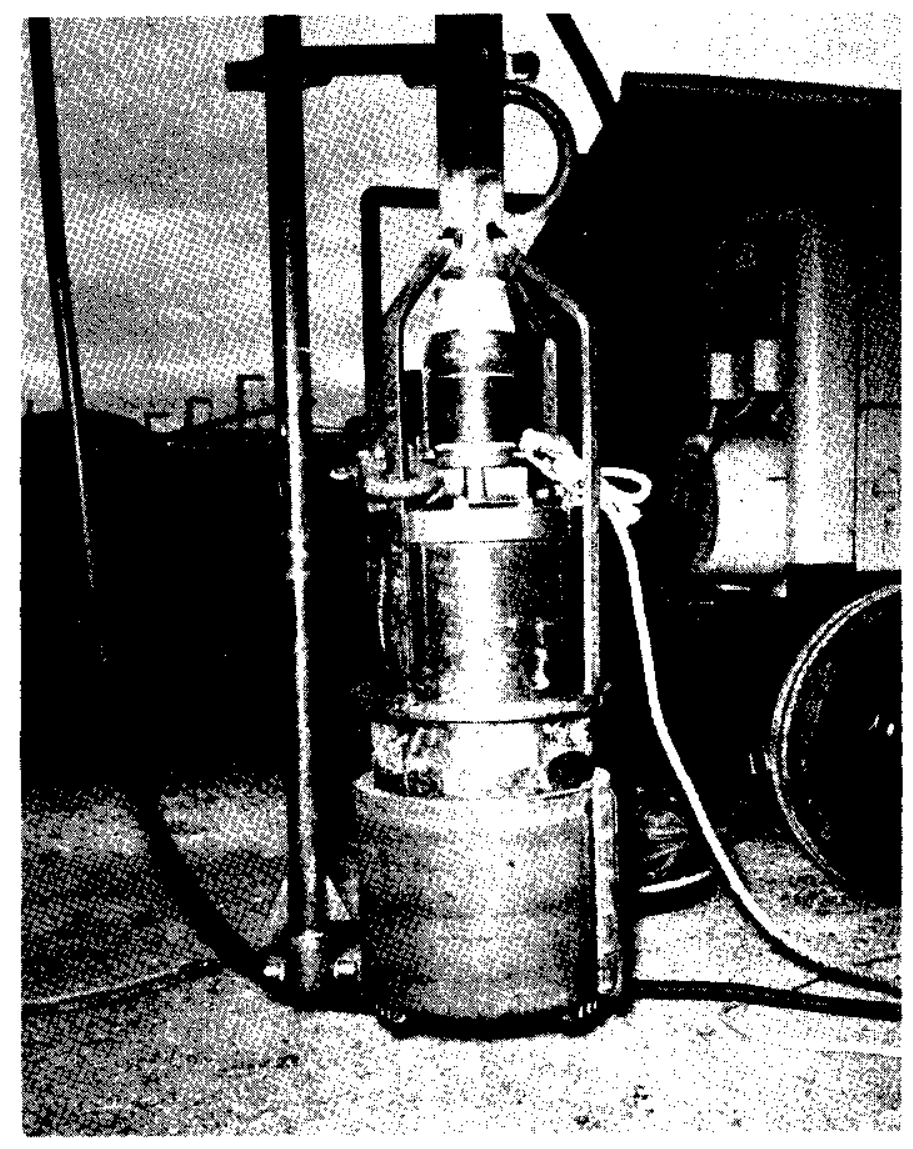

FIG. 11a. CENTRIFUGAL PUMP AND HIGH PRESSURE NOZZLE ASSEMBLY 


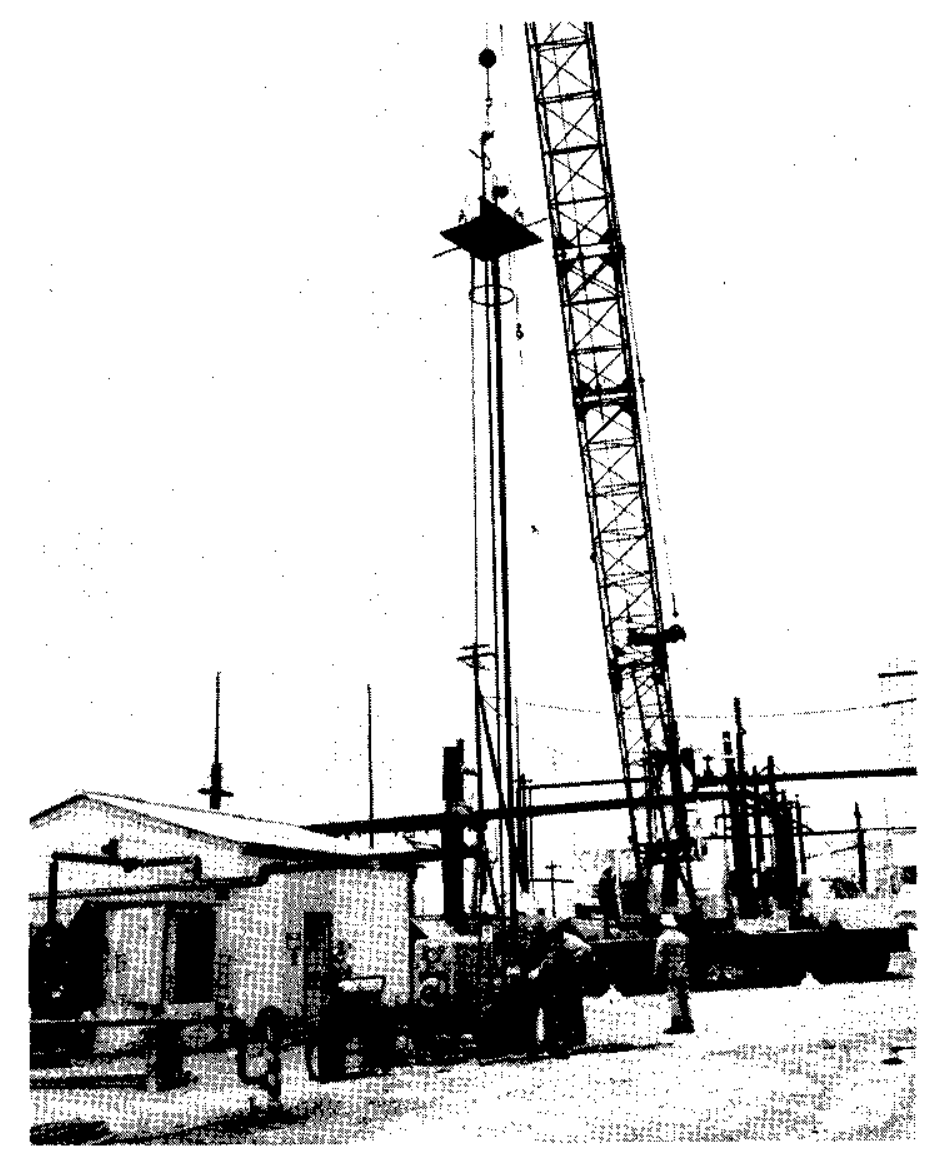

FIG. 11b. INSTALLATION OF CENTRIFUGAL PUMP AND NOZZLE ASSEMBLY

All discharge lines from the sludge pumps were shielded with concrete blocks in the vicinity of the tank (Figure 12), except at the point of exit from the riser cover plates, where lead was used to conserve space.

Water for the six high pressure pumps was obtained at 125-1b pressure from a manifold of 4 -inch pipe that was fed by a fire hydrant through 250 feet of two 2-1/2-inch fire hoses. Connection from the manifold to each pump was also made with fire hose. The high pressure discharge lines from the six pumps joined in a 4-inch pipe manifold leading directly to the top of Tank 2. Connections from this manifold to each of the four vertical pipes in the tank were made with two flexible high pressure hoses (Figure 13). All valves were operated manually on the water lines and on the waste discharge lines from the sludge pumps. 


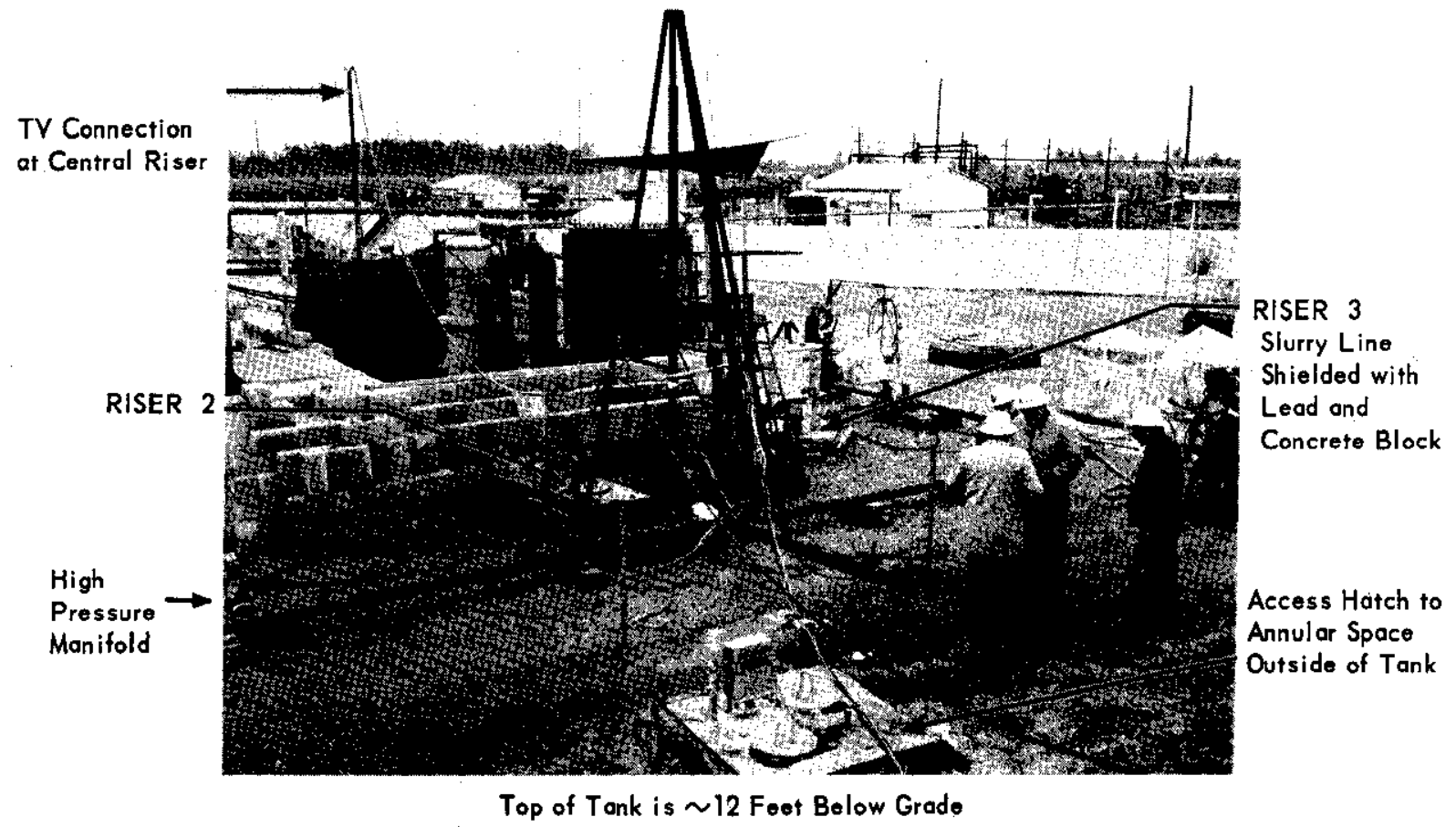

FIG. 12 SHIELDING FOR SLUDGE REMOVAL

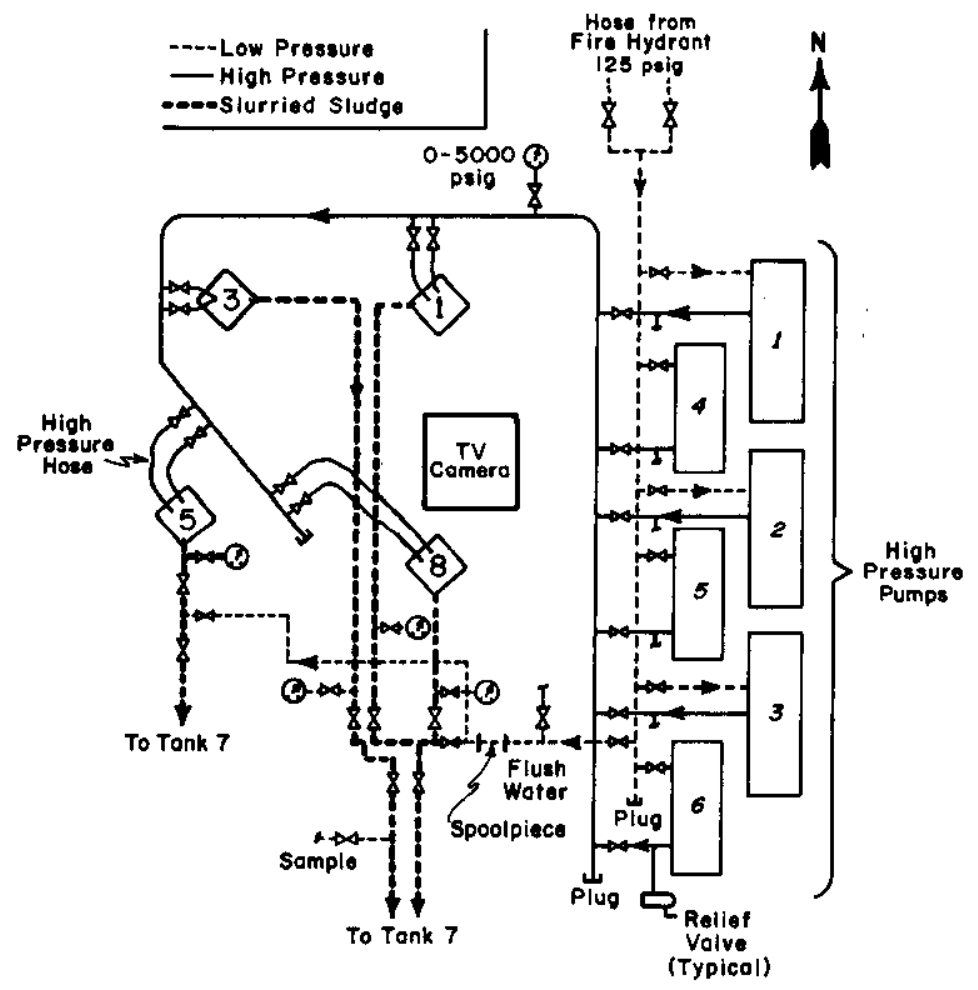

FIG. 13 PIPES AND CONTROLS FOR SLUDGE REMOVAL 


\section{Sludge Transfer Operation}

For the test, the high pressure fets were started $10 \mathrm{~min}-$ utes before the centrifugal pumps were turned on, to avold the possibility of plugging the vertical section of the discharge pipes with undiluted sludge. According to procedures established at the semiworks, the water pressure to the jet nozzles was maintained at 500 psig for 1 hour and then increased in 500 psig steps, of 1 hour each, to 2000 psig.

The inftial liquid level of 29.5 inches $(80,000$ gallons) of total sludge and supernatant solution in Tank 2 was maintained during the first 3 hours of operation by adfustment of the valves on the discharge lines from the sludge pumps. During the fourth hour the liquid level in the tank was reduced from 29.5 to 20 inches and held at 20 inches during the fifth hour while the jets were operated at 3000 psig. The liquid level was then reduced to 8 inches $(21,600$ gallons).

After $1-1 / 4$ hours of additional jetting at $2500-3000$ psig, the sludge transfer operation was shut down, and the centrifugal pump at Riser 5 was lowered to the bottom of the tank so that the residual water and sludge mixture could be pumped to a final depth of $\sim 3$ inches.

Figure 14 summarizes the schedule for nozzle pressure, the total volume of fluid pumped from Tank 2 , and the changes in liquid level in the tank.

About 43,000 gallons (90\%) of the original sludge, was removed with 230,000 gallons of water in 6 hours and 45 minutes of pumpout time. The volume ratio of the water used to the sludge removed was 5.3. An additional 65,000 gallons of resldual supernatant liquid from Tank 2 was also transferred with the sludge, so that the overall volume pumped to Tank 7 was 305,000 gallons. In Tank 7, the sludge settled rapidly to about 34 inches in 5 days, and to 28 inches in 2 weeks. This volume is approximately twice the original volume in Tank 2, and corresponds to that observed with slurried clay in the semiworks tests. The increase is attributed to aeration and some shearing of agglomerated solid material by the high velocity jets.

The operations were observed with a television camera in the center riser pipe, by measurements of liquid level in the tanks, radiation surveys of the discharge lines, and samples of slurry from one line from the discharge manifold. The initial sample of slurry was taken after 3 hours of operation, when 76,000 gallons had been transferred, and contained 14 vol $\%$ sludge after 

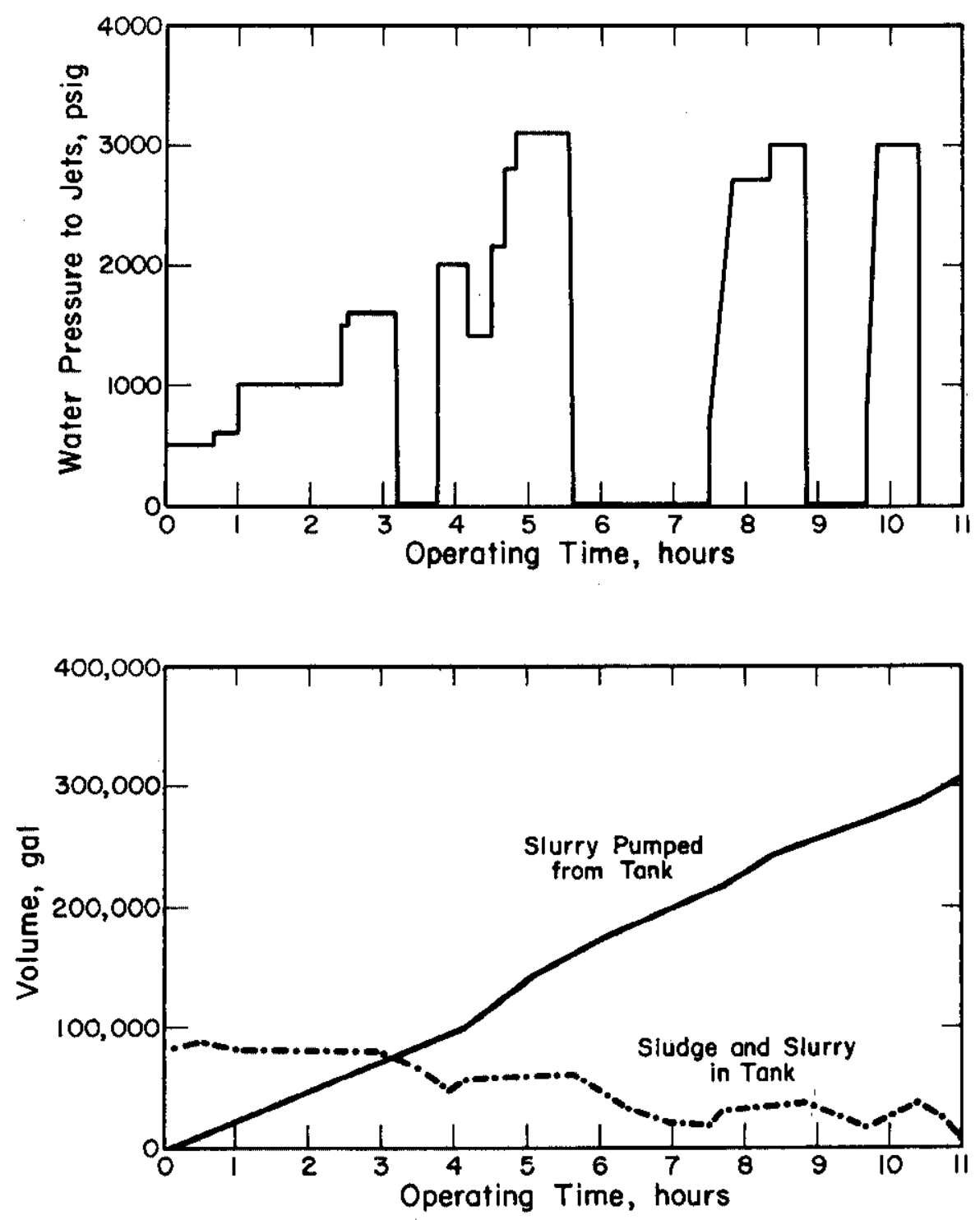

FIG. 14 SLUDGE TRANSFER DATA

centrifugation. The second sample, taken after 5 hours with 156,000 gallons transferred, contalned 25 vol \% sludge. The final sample, taken Just before shutdown with 286,000 gallons transferred, contained 11 vol $\%$ sludge.

The radiation from the discharge lines was 8 to $12 \mathrm{R} / \mathrm{hr}$ at the start of sludge removal, and decreased gradually to $2 \mathrm{R} / \mathrm{hr}$ during the first 3 hours. When the sludge pumps were turned of $f$, the radiation from the discharge lines dropped promptly to 40$60 \mathrm{mR} / \mathrm{hr}$. After the discharge lines were flushed with water at the completion of sludge removal, the radiation was $8-10 \mathrm{mR} / \mathrm{hr}$. 
The bottom area of the tank around Riser 2 was surveyed visually and photographically through a periscope. The survey showed that only 3 inches of liquid remained in the tank (Figure 15). This liquid volume and the final 1l\% solid content of the pumped slurry correspond to less than $I$ inch of settled sludge on the general area of the tank. However, areas with sludge up to 4 inches deep were observed between the columns at the center of the tank, and some sludge was also seen behind other columns nearer to the wall. Thus the "equivalent average" depth of sludge was estimated to be less than 2 inches, which corresponds to $90 \%$ removal. The total sludge removed could have been increased to 95-99\% by additional slurrying with water and continued pumping.

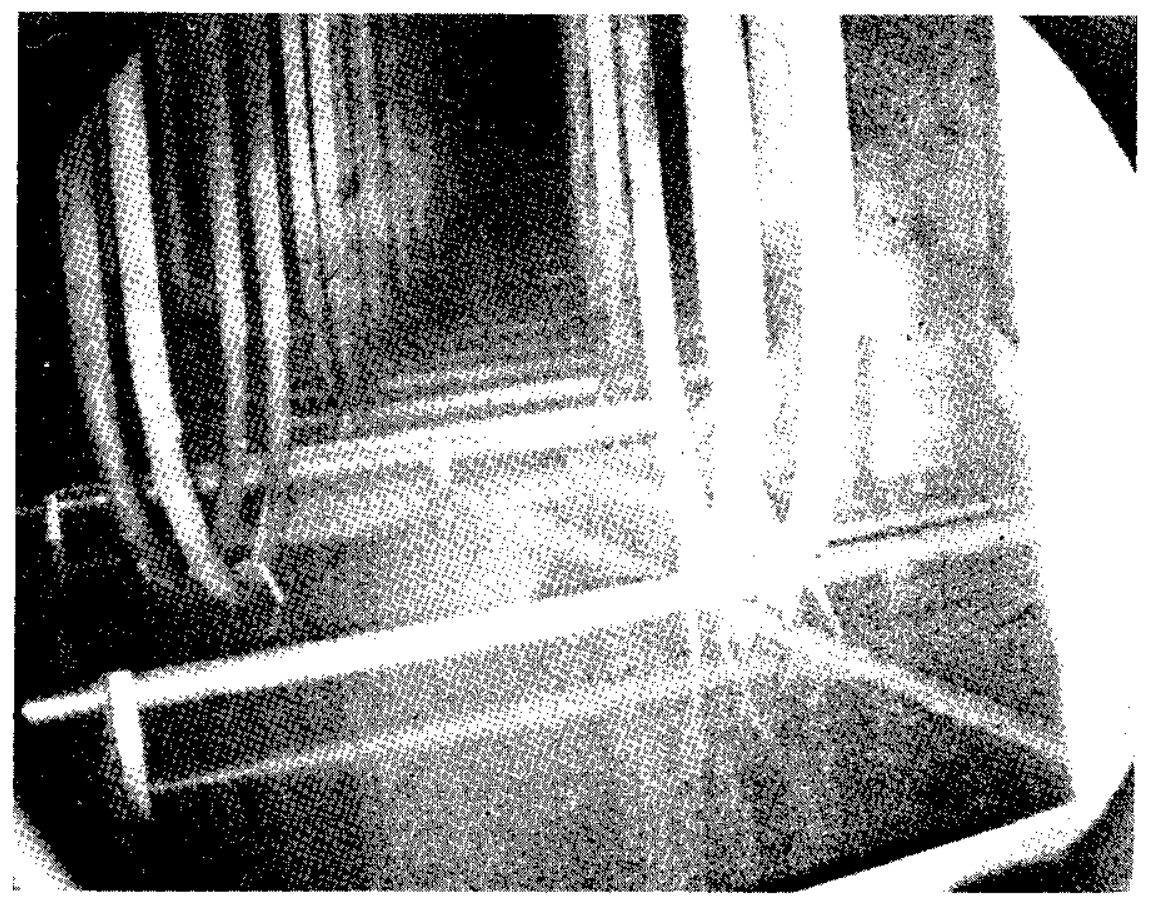

FIG. 15 BOTTOM AREA OF TANK AFTER SLUDGE REMOVAL

Following completion of the slurrying and pumpout operations, the jet and pump assemblies were removed from the tank, bagged in plastic (Figure 16), covered with tarpaulins, and stored pending further use. During removal from the tank, the assemblies were decontaminated by a ring of eight 1/16-inch high pressure jets. One of the high pressure pumps was retained to assist in the decontamination. Only low contamination was encountered on the vertical pipes down to approximately 6 feet from the bottom. The contamination increased down to the pump and jet assemblies, where the radiation was $20 \mathrm{R}$ at contact. At 500-psig pressure on the spray ring, the radiation was reduced 

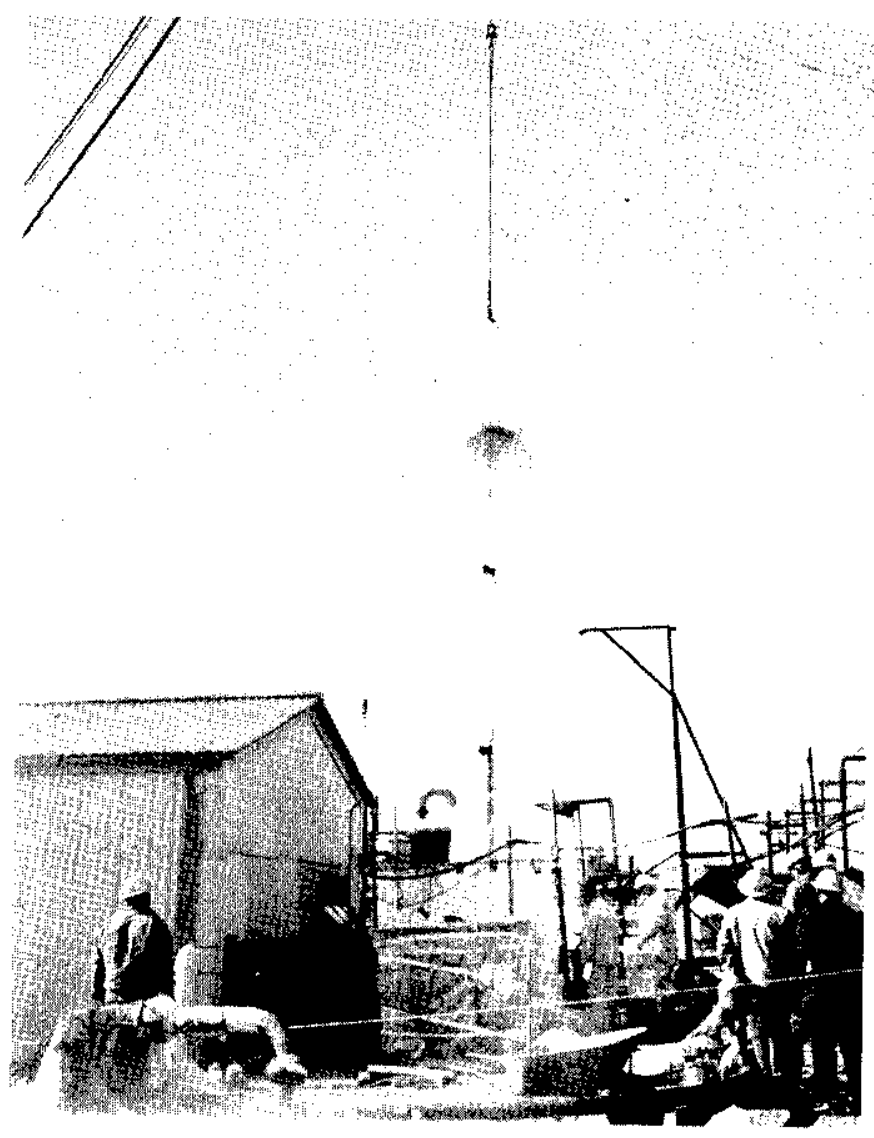

FIG. 16 REMOVAL OF NOZZLE AND PUMP ASSEMBLY

by only a factor of 2, but at 2000 psig an additional factor of 10 was obtained for a total of 20 . Even with the spray ring, $\sim 3$ hours was required to remove, decontaminate, and bag each of the first two punp and jet assemblies.

The third and fourth assemblies were removed in only 1 hour each by the use of a high pressure hand-held lance, operated at 500 to 1500 psig, to supplement the spray ring; the ring did not provide complete coverage of the external contaminated surfaces. The lance had a special fail-safe valve and a l/l6-inch nozzle. The maximum radiation from the bottom of the pumps after decontamination was 10 rads before enclosure in plastic and $3.5 \mathrm{rads}$ after enclosure. No environmental contamination occurred during the removal of sludge or subsequent removal of the equipment.

After some additional experimental work with clay in the test tank, a second plant test was made in which nearly all of the sludge in Tank 9 was transferred to Tank 13. Several minor 
changes were made to increase the efficiency and effectiveness of the operation.

- A fifth high pressure jet assembly was installed and operated intermittently in the center riser of the tank to clear this area of the bottom quickly. The experiments conducted in the experimental tank after the first plant test showed that less water would je needed with intermittent operation of a jet in the center than with jets only in the surrounding positions, since the bases of nearby columns interfered with passage of the jet streams through the center area.

- The rotation of the five jet assemblies was mechanized with reversible drive systems.

- The number of hoses from the water supply hydrant to the low pressure manifold was doubled, and more connections were installed on the manifold so that two supply hoses could be run to the larger pumps for smoother operation. The capacity of the pumping units ranged from 80 to 300 gpm at 3000 psig.

- Air-operated valves were used on the pump discharge lines so that exposure of personnel to radiation while opening and closing the valves was eliminated.

About 42,000 gallons of bottom sludge (15-1/2 inches) and 110,000 gallons of supernatant liquid waste were slurried with the high pressure jet streams and pumped from Tank 9 to Tank 13. Jet rotation rate was set by a variable speed drive at $1 / 5$ rpm at low water pressures where jet penetration was short. At water pressures greater than 1000 psig, rotation rate was reduced to $1 / 12 \mathrm{rpm}$. During the final three hours, the direction of jet rotation was reversed every half hour.

The volume of water jetted into the tank was 240,000 gallons or 5.7 times the sludge volume, and the final liquid level after pumpdown was $2-3 / 4$ inches. After settling in the receiving tank for two weeks, the transferred sludge occupied 1.6 times the volume occupied before transfer. This behavior is typical of that observed in the earlier plant test and in the expertments with clay, and is attributed to the shearing action of the jets on the sludge and to aeration.

Periscopic examination of the tank through Riser 6 following sludge removal revealed no visible sludge. Flush and decontamination water had increased the liquid level from 2-3/4 to $5-3 / 4$ inches, masking whatever sludge may have remained in 
the tank. No sludge was seen above the surface of the liquid. In a limited area under the periscope, where the incident angle of view was high, submerged colls free of sludge were clearly vistble and no sludge accumulations could be seen.

\section{Closed Circuit Television}

For the first plant test, a small television camera mounted on an adjustable mast with a remotely operated pan-and-tilt mechanism was installed in the center riser of Tank 2 (Figure 17). The camera was protected from molsture and contamination by a plastic cover. Two spotlights on a separate mast adjacent to the camera provided illumination. In preliminary surveys of the tank, the plastic cover was removed because it interfered with the lens of the camera.

Although some difficulty was experienced in coordinating the movement of the lights with the camera to scan various areas of the tank bottom, the television proved to be very valuable as a guide to progress during a sludge removal. A short circuit in the camera prevented inspection of the bottom of the tank after the sludge removal operation was completed: water vapor condensed on the mast and ran into the high voltage circuit at the back of the camera.

For the second test, a camera was completely enclosed in a water-tight aluminum box with a clear plastic window in front of the camera lens (Figure 17d). Four lights were mounted on brackets on the side of the containment box near the front and were focused along the viewing axis of the camera. Although no problem was encountered with condensation, heat from the spotlights raised the temperature in the camera high enough to cause excessive distortion of the picture. Tests conducted in advance showed that the camera alone would not generate enough heat in the box to disturb the picture. In future instaliations, the containment box will be air cooled. 


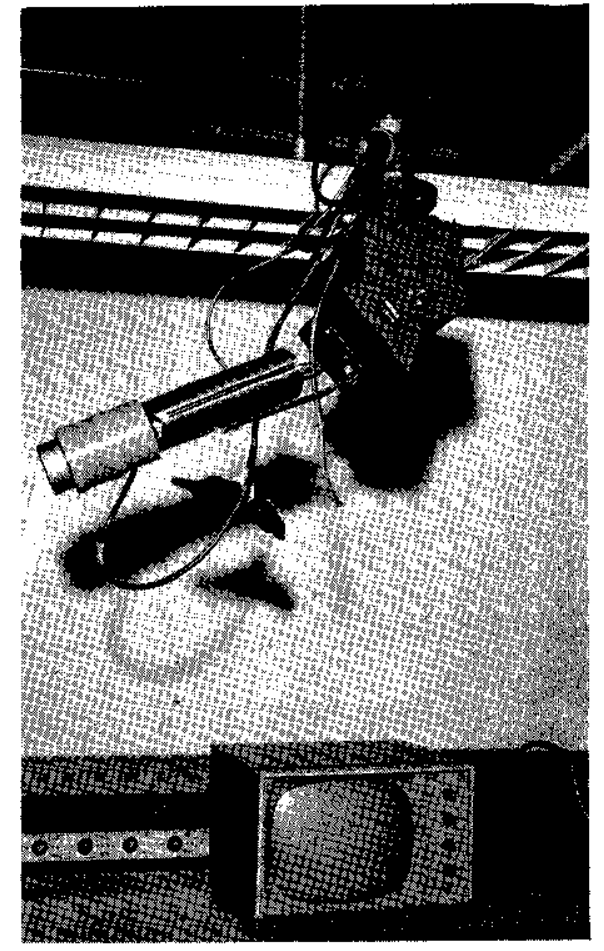

a. Camera on Pan-Tilt Mount

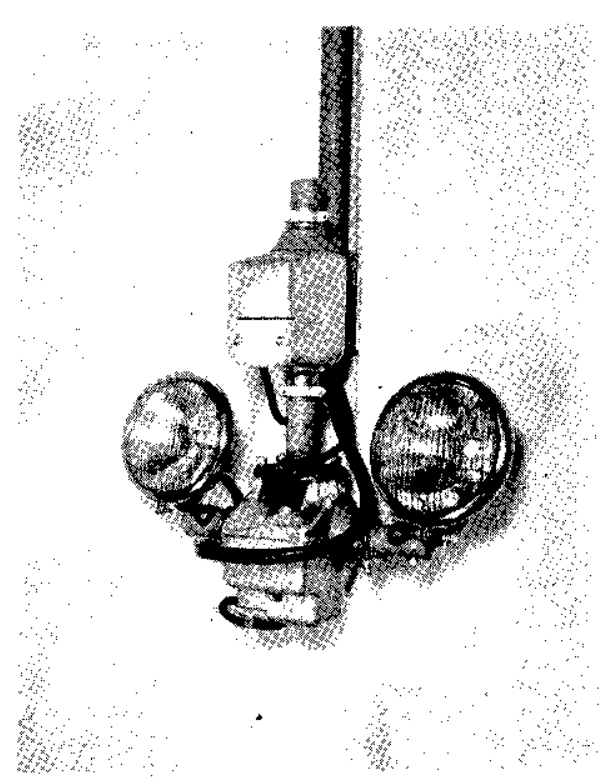

c. Lights in Plastic Containment for First Plant Test

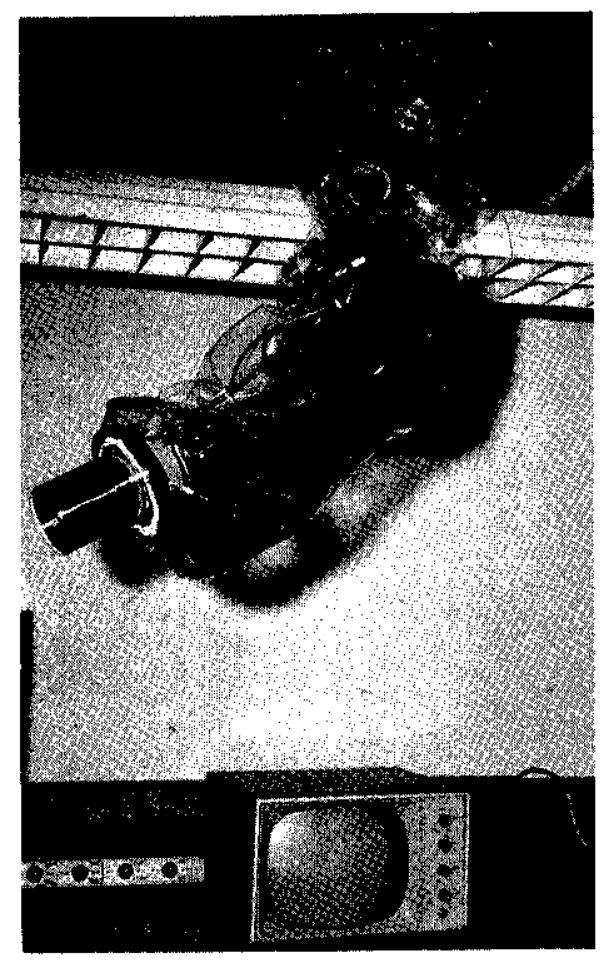

b. Camera in Plastic Containment for First Plant Test

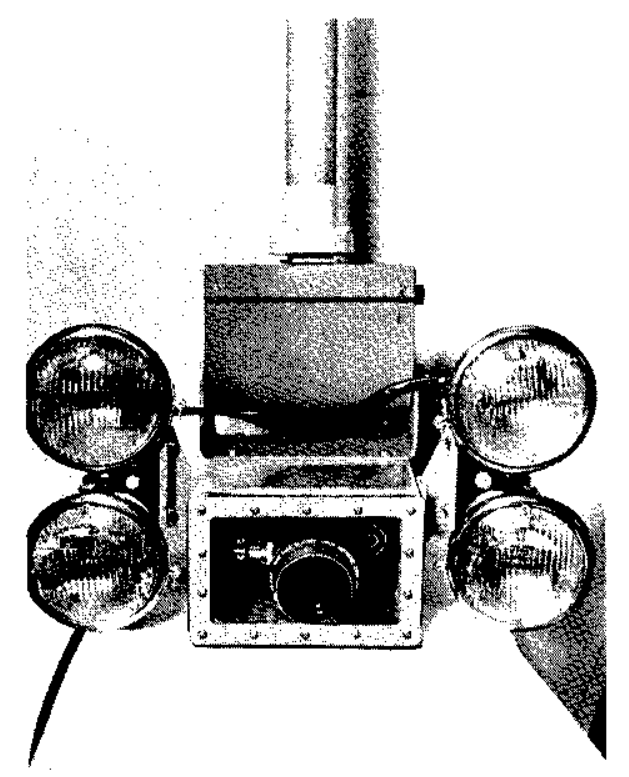

d. Enclosed Camera with Lights in Second Plant Test

FIG. 17 TELEVISION CAMERAS AND LIGHTS 